\title{
Algoriphagus antarcticus sp. nov., a novel psychrophile from microbial mats in Antarctic lakes
}

Correspondence

Stefanie Van Trappen

stefanie.vantrappen@UGent.be

\author{
Stefanie Van Trappen, Ilse Vandecandelaere, Joris Mergaert \\ and Jean Swings
}

Laboratorium voor Microbiologie, Vakgroep Biochemie, Fysiologie en Microbiologie, Universiteit Gent, K. L. Ledeganckstraat 35, B-9000 Gent, Belgium

\begin{abstract}
A taxonomic study was performed on six strains isolated from microbial mats of lakes Reid, Fryxell and Ace in Antarctica. Phylogenetic analysis based on 16S rRNA gene sequences indicated that these strains belonged to the family 'Flexibacteraceae' and were closely related to the recently described genera Algoriphagus and Hongiella. The isolates were Gram-negative, chemoheterotrophic, aerobic, psychrophilic, orange-red-pigmented bacteria and their DNA $\mathrm{G}+\mathrm{C}$ content ranged from 39.9 to $41.0 \mathrm{~mol} \%$. Whole-cell fatty acid profiles included mainly branched fatty acids and summed feature 3 , comprising $15: 0$ iso $2 \mathrm{OH}, 16: 1 \omega 7 \mathrm{c}$ or both. On the basis of genotypic, phenotypic, chemotaxonomic and phylogenetic results, the novel strains were classified as Algoriphagus antarcticus sp. nov. The type strain is LMG $21980^{\top}$ $\left(=\mathrm{DSM} 15986^{\top}=\mathrm{R}-10710^{\top}\right)$.
\end{abstract}

Members of the Cytophaga-Flavobacterium cluster constitute one of the dominant bacterial groups in the marine environment (Bowman et al., 1997; Pinhassi et al., 1997; Glöckner et al., 1999) and it is now thought that they play an important role in remineralization processes in aquatic systems (Kirchman, 2002). Recently, new genera of the 'Flexibacteraceae' have been described such as Reichenbachia, Algoriphagus, Hongiella and Belliella (Nedashkovskaya et al., 2003; Bowman et al., 2003; Yi \& Chun, 2004; Brettar et al., 2004) isolated from sea water, sea ice, algal mats of saline lakes and tidal flat sediment. Only one strain (strain A230 of Algoriphagus ratkowskyi) was isolated from a cyanobacterial mat sample from Ace Lake, Antarctica.

During the MICROMAT project (November 1998February 2001), 746 bacterial strains were isolated under heterotrophic conditions from microbial mat samples collected from ten Antarctic lakes in the Vestfold Hills (lakes Ace, Druzhby, Grace, Highway, Pendant, Organic and Watts), the Larsemann Hills (Lake Reid) and the McMurdo Dry Valleys (Lakes Hoare and Fryxell) (Van Trappen et al., 2002). Numerical analysis of their fatty acid composition revealed 41 clusters, and 16S rRNA gene sequence analysis, performed on representative strains, showed that they belong to the $\alpha$-, $\beta$ - and $\gamma$-subclasses of the

Published online ahead of print on 23 April 2004 as DOI 10.1099/ ijs.0.02973-0.

The GenBank/EMBL/DDBJ accession numbers for the $16 \mathrm{~S}$ rRNA gene sequences of strains LMG 21482, LMG $21980^{\top}$ and LMG 21983 are AJ441012/AJ577267, AJ577141 and AJ577142, respectively.
Proteobacteria, the high- and low-G + C Gram-positives and to the phylum 'Bacteroidetes' (Van Trappen et al., 2002).

In the present work, we have studied the taxonomic relationship of six strains from fatty acid cluster 15 (as delineated by Van Trappen et al., 2002), using a polyphasic taxonomic approach. A novel species of the genus Algoriphagus is described as Algoriphagus antarcticus sp. nov.

The investigated strains were LMG $21980^{\mathrm{T}}(=\mathrm{DSM}$ $\left.15986^{\mathrm{T}}=\mathrm{R}-10710^{\mathrm{T}}\right), \quad$ LMG $21981 \quad(=\mathrm{R}-10749), \quad$ LMG 21982 (=R-10752) and LMG 21983 (=R-11427) from Lake Reid, Larsemann Hills, Antarctica, LMG 21984 (=R-8290) from Lake Fryxell, McMurdo Dry Valleys, Antarctica, and LMG 21482 (=R-9286) from Ace Lake, Vestfold Hills, Antarctica, and were isolated as described by Van Trappen et al. (2002). The strains were routinely cultivated on marine agar 2216 (Difco) at $20{ }^{\circ} \mathrm{C}$ for 4 days, except when mentioned otherwise. Strains LMG $21435^{\mathrm{T}}$ (A. ratkowskyi), LMG $21969^{\mathrm{T}}$ (Algoriphagus winogradskyi), LMG $21970^{\mathrm{T}}$ (Algoriphagus chordae) and LMG $21971^{\mathrm{T}}$ (Algoriphagus aquimarinus) were routinely cultivated on marine agar 2216 (Difco) at $20^{\circ} \mathrm{C}$, whilst strain LMG $22067^{\mathrm{T}}$ (Algoriphagus halophilus) was cultivated on marine agar 2216 (Difco) at $28^{\circ} \mathrm{C}$.

DNA extracts were prepared using the method of Pitcher et al. (1989). The almost-complete $16 \mathrm{~S}$ rRNA gene sequences (1462-1491 nucleotides) of strains LMG 21482, LMG $21980^{\mathrm{T}}$ and LMG 21983 were amplified by PCR using conserved primers (Coenye et al., 1999). PCR products were purified using the QIAquick PCR Purification kit (Qiagen) according to the instructions of the manufacturer. 
Sequence analysis was performed using an automatic DNA sequencer (ABI Prism 3100; Applied Biosystems), applying a BigDye Terminator Cycle Sequencing v2.0 Ready Reaction kit (Applied Biosystems), following the protocols of the manufacturer. Sequence assembly was performed using the program AutoAssembler 1.4.0 (Applied Biosystems). The closest related sequences were found using the FASTA program, the sequences from reference strains were aligned and editing of the alignment and reformatting was performed using the BioEdit program (Hall, 1999) and ForCon (available at http://www.ebi.ac.uk/embnet.news/vol6_1/ ForCon/body_forcon.html) (Raes \& Van De Peer, 1999). Evolutionary distances were calculated using the Jukes and Cantor evolutionary model and a phylogenetic tree (Fig. 1) was constructed using the neighbour-joining method (Saitou \& Nei, 1987) with the TREECON program (Van De Peer \& De Wachter, 1994). Dendrograms obtained by maximum-parsimony and maximum-likelihood analyses showed essentially the same topography (data not shown).

The results of the phylogenetic analysis revealed that the novel strains belonged to the recently described genus Algoriphagus within the family 'Flexibacteraceae' (Bowman et al., 2003; Nedashkovskaya et al., 2004), which is most closely related to the genera Hongiella, Belliella and Cyclobacterium (see Fig. 1). The Antarctic strains formed a robust branch, supported by a high bootstrap value (100\% of the bootstrap replications for all methods).

The 16S rRNA gene sequences of strains LMG $21980^{\mathrm{T}}$ and LMG 21983 were identical to each other, whilst the sequence of LMG 21482 differed by only one base from these sequences $(99.9 \%$ similarity). The $16 \mathrm{~S}$ rRNA gene sequences of the novel strains showed $98.7 \%$ sequence similarity to that of $A$. chordae, $98.7 \%$ to that of A. ratkowskyi, $98 \cdot 6 \%$ to that of $A$. winogradskyi, $98 \cdot 5 \%$ to that of A. aquimarinus, $97 \cdot 4 \%$ to A. halophilus, $94 \cdot 7 \%$ to that of Hongiella ornithinivorans, $93.8 \%$ to that of Hongiella mannitolivorans, $92.9 \%$ to that of Belliella baltica, $92.9 \%$ to that of Cyclobacterium marinum and less than $90 \%$ to sequences of other related genera.

Genomic relatedness between the novel strains and their most closely related phylogenetic neighbours (A. ratkowskyi, A. chordae, A. aquimarinus, A. winogradskyi and A. halophilus) was determined by DNA-DNA hybridizations, carried out with photobiotin-labelled probes in microplate wells as described by Willems et al. (2001), using an HTS7000 Bio Assay Reader (Applied Biosystems) for the fluorescence measurements. The hybridization temperature was $34^{\circ} \mathrm{C}$ and reciprocal experiments were performed for every pair of strains. The mean hybridization level

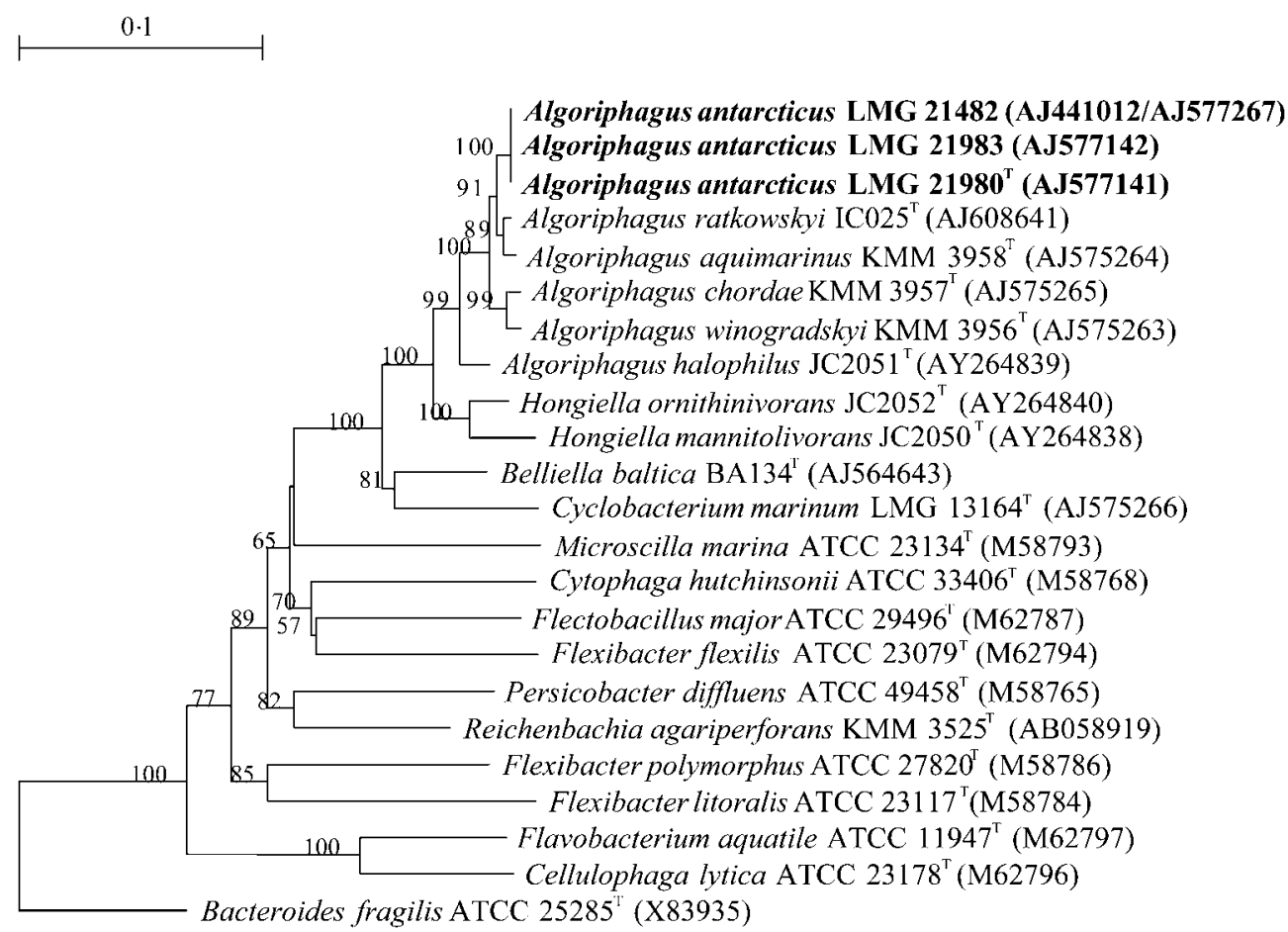

Fig. 1. Neighbour-joining dendrogram showing the estimated phylogenetic relationships of $A$. antarcticus and related members of the family 'Flexibacteraceae' on the basis of 16S rRNA gene sequences. Bacteroides fragilis was chosen as the outgroup. Bootstrap values are shown in percentages of 500 replicates when more than $50 \%$. Bar, 1 nucleotide substitution per 10 nucleotides. The GenBank/EMBL/DDBJ accession number for each reference strain is shown in parentheses. 
between the strains LMG $21980^{\mathrm{T}}$, LMG 21981, LMG 21982, LMG 21983 and LMG 21984 ranged from $89 \cdot 0$ to $98 \cdot 7 \%$, while strain LMG 21482 showed a hybridization value of only $74 \cdot 2 \pm 3 \cdot 9 \%$ with strain LMG $21980^{\mathrm{T}}$ and $72 \cdot 7 \pm 0 \cdot 5 \%$ with strain LMG 21983. Hybridization values of LMG $21980^{\mathrm{T}}$ and LMG 21983 with the nearest phylogenetic neighbours A. ratkowskyi (LMG $21435^{\mathrm{T}}$ ), A. chordae (LMG $\left.21970^{\mathrm{T}}\right)$, A. aquimarinus $\left(\mathrm{LMG} 21971^{\mathrm{T}}\right.$ ) and $A$. winogradskyi (LMG $21969^{\mathrm{T}}$ ) ranged from $20 \cdot 5$ to $38 \cdot 6 \%$. The hybridization value between the strains LMG 21983 and LMG $22067^{\mathrm{T}}$ (A. halophilus) was only $7 \cdot 2 \%$. Differences between reciprocal experiments were less than $8 \%$. These results clearly showed that the Antarctic strains represented a novel species within the genus Algoriphagus.

The $\mathrm{G}+\mathrm{C}$ content of the DNA from the novel strains was determined using an HPLC method, as described by Van Trappen et al. (2003). The G+C values of strains LMG 21482, LMG 21980 ${ }^{\mathrm{T}}$, LMG 21981, LMG 21982, LMG 21983 and LMG 21984 were $40 \cdot 8,40 \cdot 6,40 \cdot 6,40 \cdot 6,39 \cdot 9$ and $41.0 \mathrm{~mol} \%$, respectively. These values are consistent with the $\mathrm{G}+\mathrm{C}$ content of the genus Algoriphagus, which ranges from 35 to $42 \mathrm{~mol} \%$ (Bowman et al., 2003; Nedashkovskaya et al., 2004).

Cellular fatty acid patterns of the novel strains were based on the data generated by Van Trappen et al. (2002). The strains showed similar fatty acid profiles and the mean composition was $3 \cdot 4 \% 15: 0$ anteiso, $23 \cdot 1 \% 15: 0$ iso, $4 \cdot 1 \%$ $15: 0$ iso $3 \mathrm{OH}, 9 \cdot 3 \% 15: 1$ iso, $1 \cdot 8 \% 16: 03 \mathrm{OH}, 1 \cdot 9 \% 16: 0$ iso, $2.5 \% 16: 0$ iso $3 \mathrm{OH}, 2 \cdot 9 \% 16: 1$ iso, $4.9 \% 16: 1 \omega 5 c$, $12 \cdot 5 \% 17: 0$ iso $3 \mathrm{OH}, 3 \cdot 4 \% 17: 1 \omega 9 \mathrm{c}$ iso, $24 \cdot 3 \% 15: 0$ iso $2 \mathrm{OH}$ and/or $16: 1 \omega 6 c$. Other fatty acids each accounted for less than $1 \%$. The fatty acid profiles of the novel strains resembled those determined for the other Algoriphagus species but differed in terms of relative amounts of $15: 0$ iso, $15: 1$ iso, $17: 0$ iso $3 \mathrm{OH}$ and $15: 0$ iso $2 \mathrm{OH} / 16: 1 \omega 6 c$ (Bowman et al., 2003; Nedashkovskaya et al., 2004).

Morphological, physiological and biochemical tests were performed, as described earlier (Van Trappen et al., 2003). The strains showed typical morphological characteristics of the genus Algoriphagus (Bowman et al., 2003; Nedashkovskaya et al., 2004) and their physiological and

Table 1. Phenotypic characteristics differentiating Algoriphagus antarcticus sp. nov. and related species

Species: 1, A. antarcticus; 2, A. winogradskyi; 3, A. chordae; 4, A. aquimarinus; 5, A. ratkowskyi; 6, A. halophilus; 7, H. mannitolivorans; 8, H. ornithinivorans; 9, B. baltica; 10, C. marinum. Symbols: +, positive test; -, negative test; V, variable between strains; ND, no available data; O, orange; R, red; P, pink. Data from Bowman et al. (2003), Yi \& Chun (2004), Brettar et al. (2004), Nedashkovskaya et al. (2004) and this study.

\begin{tabular}{|c|c|c|c|c|c|c|c|c|c|c|}
\hline & 1 & 2 & 3 & 4 & 5 & 6 & 7 & 8 & 9 & 10 \\
\hline Colour of cell mass & $\mathrm{O}-\mathrm{R}$ & $\mathrm{O}-\mathrm{R}$ & $\mathrm{O}-\mathrm{R}$ & $\mathrm{O}-\mathrm{R}$ & $\mathrm{P}$ & $\mathrm{O}-\mathrm{R}$ & $\mathrm{O}$ & $\mathrm{O}$ & $\mathrm{P}-\mathrm{O}$ & $\mathrm{P}-\mathrm{R}$ \\
\hline $10 \% \mathrm{NaCl}$ & - & - & + & + & - & + & - & + & - & + \\
\hline $25^{\circ} \mathrm{C}$ & + & + & + & + & + & + & + & + & + & + \\
\hline $30{ }^{\circ} \mathrm{C}$ & - & + & + & + & - & + & + & + & + & + \\
\hline \multicolumn{11}{|l|}{ Production of: } \\
\hline Oxidase & + & + & + & + & + & + & + & + & + & + \\
\hline Catalase & + & + & + & + & - & + & + & + & + & + \\
\hline Acid from carbohydrates & - & + & + & + & + & - & - & - & $\mathrm{v}$ & + \\
\hline \multicolumn{11}{|l|}{ Hydrolysis of: } \\
\hline Chitin & - & - & - & - & $\mathrm{v}$ & - & - & - & - & - \\
\hline CM-cellulose & - & - & - & - & - & - & - & - & - & ND \\
\hline DNA & - & - & - & + & - & - & + & + & + & - \\
\hline Gelatin & - & + & - & + & - & + & + & + & - & - \\
\hline Starch & - & + & - & - & $\mathrm{v}$ & - & + & + & + & - \\
\hline Tween 80 & ND & - & - & + & - & + & - & + & ND & - \\
\hline Urea & - & - & - & - & - & - & - & - & $\mathrm{ND}$ & - \\
\hline $\mathrm{G}+\mathrm{C}$ content $(\mathrm{mol} \%)$ & 40 & 41 & 40 & 41 & 35 & 37 & 42 & 38 & 35 & 36 \\
\hline
\end{tabular}


biochemical characteristics are given in the description. The results of the polyphasic analysis supported the recognition of a novel species within the genus Algoriphagus and the name Algoriphagus antarcticus sp. nov. is proposed. The novel species can be clearly differentiated from related Algoriphagus and Hongiella species by several phenotypic characteristics (see Table 1).

\section{Description of Algoriphagus antarcticus sp. nov.}

Algoriphagus antarcticus (ant.arc'ti.cus. L. masc. adj. antarcticus of the Antarctic, the environment from where the strains were isolated).

The rod-shaped cells range from 2 to $3 \mu \mathrm{m}$ in length and up to $0.5 \mu \mathrm{m}$ in width; motility not detected. The strains grow at $5-20{ }^{\circ} \mathrm{C}$, with weak growth at $25^{\circ} \mathrm{C}$ and an optimal growth temperature of $20^{\circ} \mathrm{C}$. No growth occurs at $30^{\circ} \mathrm{C}$. Orange-red-pigmented, convex, opaque colonies with a diameter of $0.5-3 \mathrm{~mm}$ with entire margins are formed on marine agar plates after 6 days incubation. Colonies on Anacker \& Ordal's agar are flat, round with entire margins and $0.5-0.7 \mathrm{~mm}$ in diameter after 14 days incubation. Growth also occurs on nutrient agar and R2A and colonies do not adhere to the agar. No growth on trypticase soy agar. Gram-negative and catalase- and oxidase-positive. Degrades aesculin. Growth is not observed (API 20NE) on glucose, mannose, maltose, L-arabinose, mannitol, $\mathrm{N}$-acetylglucosamine, gluconate, caprate, adipate, malate, citrate and phenylacetate. Acids are not produced from carbohydrates (API 20E). Agar, alginate, pectin, chitin, casein, CM-cellulose, DNA, starch, gelatin, tyrosine and urea are not degraded. Congo red is not absorbed. There is no production of a brown diffusible pigment on L-tyrosine agar and no precipitate is formed on egg-yolk agar. Tests for indole production, citrate utilization, nitrate reduction, the Voges-Proskauer reaction and hydrogen sulfide production are negative. None of the strains shows activity for the enzymes arginine dihydrolase, lysine decarboxylase, ornithine decarboxylase, tryptophan deaminase (API 20E), lipase (C14), cystine arylamidase (except strain LMG 21983), $\alpha$-galactosidase, $\beta$-glucuronidase, $\alpha$-mannosidase and $\alpha$ fucosidase (API ZYM). Weak enzymic activity is observed for esterase (C4), esterase lipase (C8), $\alpha$-glucosidase and $\beta$-glucosidase, medium activity for valine arylamidase and $\beta$-galactosidase, and strong activity for alkaline and acid phophatases, leucine arylamidase, trypsin, $\alpha$-chymotrypsin and naphthol-AS-BI-phosphohydrolase. Variable results are obtained for $N$-acetyl- $\beta$-glucosaminidase. Growth occurs in up to $5 \% \mathrm{NaCl}$ but not in $10 \% \mathrm{NaCl}$, indicating that the strains are not halophilic but are moderately halotolerant. The G+C content of the strains is 39.9$41.0 \mathrm{~mol} \%$. Isolated from microbial mats from lakes Reid, Fryxell and Ace, Antarctica.

The type strain is LMG $21980^{\mathrm{T}} \quad\left(=\mathrm{DSM} \quad 15986^{\mathrm{T}}=\right.$ $\left.\mathrm{R}-10710^{\mathrm{T}}\right)$.

\section{Acknowledgements}

This work was funded by the Bijzonder Onderzoeksfonds (BOF), Universiteit Gent, Belgium. Part of this work was conducted in the framework of the MICROMAT project 'Biodiversity of microbial mats in Antarctica' (project no. BIO4980040), funded by the European Commission under the Biotech Programme.

\section{References}

Bowman, J. P., McCammon, S. A., Brown, M. V., Nichols, D. S. \& McMeekin, T. A. (1997). Diversity and association of psychrophilic bacteria in Antarctic sea ice. Appl Environ Microbiol 63, 3068-3078.

Bowman, J. P., Nichols, C. M. \& Gibson, J. A. E. (2003). Algoriphagus ratkowskyi gen. nov., sp. nov., Brumimicrobium glaciale gen. nov., sp. nov., Cryomorpha ignava gen. nov., sp. nov. and Crocinitomix catalasitica gen. nov., sp. nov., novel flavobacteria isolated from various polar habitats. Int J Syst Evol Microbiol 53, 1343-1355.

Brettar, I., Christen, R. \& Höfle, M. G. (2004). Belliella baltica gen. nov., sp. nov., a novel marine bacterium of the CytophagaFlavobacterium-Bacteroides group isolated from surface water of the central Baltic Sea. Int J Syst Evol Microbiol 54, 65-70.

Coenye, T., Falsen, E., Vancanneyt, M., Hoste, B., Govan, J. R., Kersters, K. \& Vandamme, P. (1999). Classification of Alcaligenes faecalis-like isolates from the environment and human clinical samples as Ralstonia gilardii sp. nov. Int J Syst Bacteriol 49, 405-413.

Glöckner, F. O., Fuchs, B. M. \& Amann, R. (1999). Bacterioplankton compositions of lakes and oceans: a first comparison based on fluorescence in situ hybridization. Appl Environ Microbiol 65, 3721-3726.

Hall, T. A. (1999). BioEdit: a user-friendly biological sequence alignment editor and analysis program for Windows 95/98/NT. Nucleic Acids Symp Ser 41, 95-98.

Kirchman, D. L. (2002). The ecology of Cytophaga-Flavobacteria in aquatic environments. FEMS Microbiol Ecol 39, 91-100.

Nedashkovskaya, O. I., Suzuki, M., Vysotskii, M. V. \& Mikhailov, V. V. (2003). Reichenbachia agariperforans gen. nov., sp. nov., a novel marine bacterium in the phylum Cytophaga-FlavobacteriumBacteroides. Int J Syst Evol Microbiol 53, 81-85.

Nedashkovskaya, O. I., Vancanneyt, M., Van Trappen, S. \& 7 other authors (2004). Description of Algoriphagus aquimarinus sp. nov., Algoriphagus chordae sp. nov. and Algoriphagus winogradskyi sp. nov., from sea water and algae, transfer of Hongiella halophila Yi and Chun 2004 to the genus Algoriphagus as Algoriphagus halophilus comb. nov. and emended descriptions of the genera Algoriphagus Bowman et al. 2003 and Hongiella Yi and Chun 2004. Int J Syst Evol Microbiol 54, 1757-1764.

Pinhassi, J., Zweifel, U. L. \& Hagström, A. (1997). Dominant marine bacterioplankton species found among colony-forming bacteria. Appl Environ Microbiol 63, 3359-3366.

Pitcher, D. G., Saunders, N. A. \& Owen, R. J. (1989). Rapid extraction of bacterial genomic DNA with guanidium thiocyanate. Lett Appl Microbiol 8, 151-156.

Raes, J. \& Van de Peer, Y. (1999). ForCon: a software tool for the conversion of sequence alignments (http://www.ebi.ac.uk/embnet. news/vol6_1/ForCon/body_forcon.html).

Saitou, N. \& Nei, M. (1987). The neighbor-joining method: a new method for reconstructing phylogenetic trees. Mol Biol Evol 4, 406-425.

Van de Peer, Y. \& De Wachter, R. (1994). TREECON for Windows: a software package for the construction and drawing of evolutionary trees for the Microsoft Windows environment. Comput Appl Biosci 10, 569-570. 
Van Trappen, S., Mergaert, J., Van Eygen, S., Dawyndt, P., Cnockaert, M. C. \& Swings, J. (2002). Diversity of 746 heterotrophic bacteria isolated from microbial mats from ten Antarctic lakes. Syst Appl Microbiol 25, 603-610.

Van Trappen, S., Mergaert, J. \& Swings, J. (2003). Flavobacterium gelidilacus sp. nov., isolated from microbial mats in Antarctic lakes. Int J Syst Evol Microbiol 53, 1241-1245.
Willems, A., Doignon-Bourcier, F., Goris, J., Coopman, R., de Lajudie, P., De Vos, P. \& Gillis, M. (2001). DNA-DNA hybridization study of Bradyrhizobium strains. Int $J$ Syst Evol Microbiol 51, 1315-1322.

Yi, H. \& Chun, J. (2004). Hongiella mannitolivorans gen. nov., sp. nov., Hongiella halophila sp. nov. and Hongiella ornithinivorans sp. nov., isolated from tidal flat sediment. Int J Syst Evol Microbiol 54, 157-162. 